\title{
Intravital imaging of cell signaling in mice
}

\author{
Laila Ritsma, Bas Ponsioen and Jacco van Rheenen*
}

Hubrecht Institute-KNAW and University Medical Center Utrecht; Utrecht, The Netherlands

Keywords: intravital imaging, two photon microscopy, mice, biosensors, imaging windows

\begin{abstract}
Abbreviations: 2D, two dimensional; $\mathrm{MHz}$, mega hertz; ns, nanosecond; ECM, extracellular matrix; OFDI, optical frequency domain imaging; SHG, second harmonic generation; $\mathrm{kD}$, kilo dalton; CSFE, carboxy-fluorescein diacetate succinimidyl ester; $\mathrm{Grl}^{+}$, granulocyte receptor-1; GFP, green fluorescent protein; FP, fluorescent protein; cAMP, cyclic adenosine monophosphate; $\mathrm{Ca}^{2+}$, calcium; PIP, 2 , phosphatidylinositol-4,5-diphosphate; FRET, fluorescence resonance energy tranfer; CTL, cytotoxic

T lymphocyte; FLIM, fluorescence lifetime imaging microscopy; FRAP, fluorescence recovery after photobleaching;

FCS, fluorescence correlation spectroscopy; FCCS, fluorescence cross-correlation spectroscopy
\end{abstract}

Cell signaling is mostly studied in in vitro 2D-cell culture models that lack the complex in vivo environment provided by neighboring cells, soluble secreted factors and non-cellular matrix components. Given that many environmental factors control cell signaling, it comes as no surprise that in vitro observations often poorly correlate with in vivo observations. Recent developments in intravital imaging techniques have made it possible to visualize and study cell signaling in individual cells within living animals. Here, we review intravital imaging techniques based on fluorescence microscopy and give examples of how these techniques are being used to study cell signaling.

\section{Introduction}

Inter-organ, intercellular and intracellular signaling are critical events for normal function of a multi-cellular body. Many diseases result from dysfunctional signaling pathways, cancer being a notable example. In order to develop new clinical strategies for these diseases, it is essential to understand the involved signaling pathways in their pathophysiological contexts. The introduction of cell-culture in the 19th century as a common laboratory technique allowed researchers to grow cells on plastic or glass (in case of adherent cells) and concisely study their cell signaling in these 2-dimensional (2D) culture models. Based on such models, an extensive body of knowledge has been obtained on intrinsic characteristics of cells and many important signaling molecules have been discovered and signaling pathways elucidated. Nevertheless, it has become increasingly apparent that cell behavior in in vitro 2D-culture models differs from that in their physiological environment. In a living mouse, for exampe, carcinoma cells migrate with 10 times higher velocities and more persistency than has generally been observed in in vitro models. ${ }^{1}$

What makes cells behave differently in vivo compared to in vitro? 2D-culture models lack the full dimensions of integrated local and systemic positive and negative feedback signals

*Correspondence to: Jacco van Rheenen; Email: j.vanrheenen@hubrecht.eu Submitted: 04/26/12; Accepted: 05/17/12

http://dx.doi.org/10.4161/intv.20802 that control cell-physiological processes. The in vivo environment contains at least three (broad) categories of factors that impose additional cell signaling on individual cells, including: (1) neighboring cells, (2) secreted soluble factors and (3) non-cellular structural factors [extracellular matrix (ECM)]. Collectively, these factors are referred to as the microenvironment and they form the signal input of individual cells. The composition of the microenvironment is dynamic and unpredictable since microenvironmental factors are mutually influenced, leading to complex and confined cell signaling in space and time. The absence of microenvironmental factors in in vitro models systematically alters the balance of cellular signal input with subsequent changes in the localization of many signaling proteins, the regulation of signaling pathways and ultimately cell morphology and behavior (Fig. 1). Moreover, cell lines used in 2D-culture models are usually transformed to allow unlimited passaging, leading to altered cell cycle and gene expression profiles as compared to their non-transformed counterparts in living tissue. Thus, in order to fully understand physiological and pathological processes, cell behavior should ultimately be studied in its physiological environment.

For many decades, important knowledge on signaling pathways and their underlying genes have evolved from genetic and biochemical studies on mice. Several techniques, such as (q)PCR and western blotting have been routinely used to detect specific gene transcripts and protein expressions in tissue samples. As a general disadvantage, many of these analyses require large numbers of cells, thereby obscuring the signaling properties of individual cells. Moreover, most of these techniques lack spatial resolution, which would help to fully understand single cell signaling events. Therefore, histological, immunohistochemical and RNA-hybridization techniques have been successfully employed to provide spatial information with cellular (and sometimes subcellular) resolution and to assess expression levels of signaling molecules. For example, invasion of tumor cells into the surrounding stroma can be visualized by standard histological techniques that are commonly employed to grade the pathological stage of a tumor. Although histological (staining) techniques can provide spatial information with sub-cellular resolution, they do 


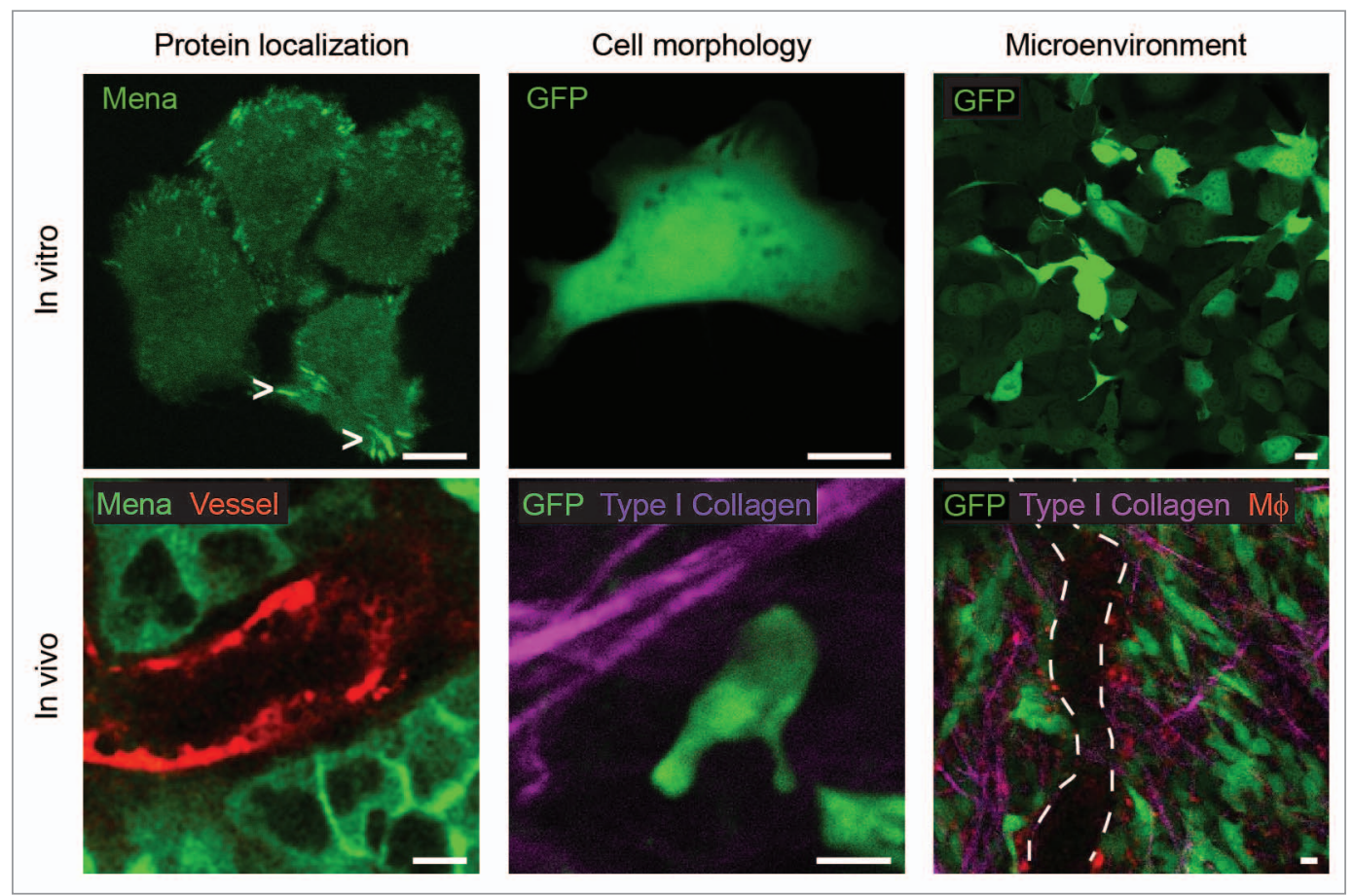

Figure 1. The in vitro $2 \mathrm{D}$ culture model does not represent the in vivo situation. High-resolution two-photon images of cells were acquired in vitro and in living tissue. Left: MTLn3 cells overexpressing GFP-Mena. Note that GFP-Mena localizes to focal adhesions (arrow heads) in vitro, whereas this cannot be observed in vivo. Middle: differential morphologies of KeP1_11-GFP cells in vitro and in vivo. Right: the microenvironment of C26-GFP cells [ECM, macrophages ( $\mathrm{m} \phi, 70 \mathrm{kD}$ Dextran) and blood vessels (dashed line)] cannot be recapitulated in vitro. Scale bar represents $5 \mu \mathrm{m}$.

not provide any temporal information. In fact, in order to monitor processes over time, samples of separate individuals would need to be obtained at several timepoints. By contrast, individual cells can be visualized over multiple time points in the same animal using intravital imaging. ${ }^{2-4}$ In this review, we will give a historical overview of high-resolution intravital imaging techniques, followed by examples of how intra- and intercellular signaling can be studied. Finally, we will describe the latest developments in intravital imaging.

\section{Historical Overview of Intravital Imaging Techniques}

The importance of in vivo measurements became evident already in 1839, when intravital imaging was first described by Wagner. He observed the interaction of leukocytes with the blood vessel wall in the webbed feet of a grass frog using bright field transillumination. ${ }^{5}$ In these early days, most intravital imaging studies could only examine the vasculature and the microcirculation, due to the old-fashioned optics and the lack of contrasting techniques to visualize other tissues. This changed in 1911, when Heimstadt introduced the first fluorescence microscope. ${ }^{6}$ Together with the development of exogenous fluorophores, ${ }^{7}$ the fluorescence microscope allowed in vivo imaging of intravenously injected fluorophores and these "circulating sources of light" were visualized in several tissues such as liver and kidney. ${ }^{8}$ Nonetheless, the earliest observations were done merely by eye or diafilms, ${ }^{9}$ limiting these studies to descriptive reports on relatively large-scale events.
In the mid and late 20th century new lasers, optics and detectors were developed, leading to the introduction of video (widefield) and confocal microscopy. In contrast to earlier versions of fluorescence microscopes, these advanced microscopes could record images and therefore allowed post-acquisitional image analysis and publication of the experimental images. ${ }^{10,11}$ In addition, the confocal microscope was designed to eliminate out-offocus emission light (from beyond the optical section) by virtue of a pinhole, resulting in contrast enhancement (making subcellular structures clearer) and improved Z-resolution. Thereby it constructs optical sections through tissue without physically sectioning it (Fig. 2A). Since its first biological implementation in $1987,{ }^{12,13}$ confocal microscopes have been applied to study numerous (subcellular) events in living mice such as tumor cell migration in mammary tumors. ${ }^{14}$ Spinning disk confocal microscopes have been used in several studies because it allows fast scanning and therefore induces little phototoxicity. ${ }^{15}$

Nowadays, the most advanced confocal microscopes are equipped with several lasers in the visible light spectrum (400$650 \mathrm{~nm}$ ) to excite a diversity of fluorophores. However, scattering of visible light in tissue limits the imaging depth. This problem is overcome by exciting fluorophores with infrared lasers (< 1,000 $\mu \mathrm{m}$ deep) (Fig. 2A).$^{16}$ In 1990, Denk et al. developed the ultrashort pulsed laser ${ }^{17}$ in which all photons over a time span of 12.5 ns are concentrated into a femtosecond pulse (for a $80 \mathrm{MHz}$ pulsed laser). In the focal plane, the photon density within such a pulse is sufficient to make fluorophores absorb two photons nearly simultaneously (Fig. 2B) (this was predicted 


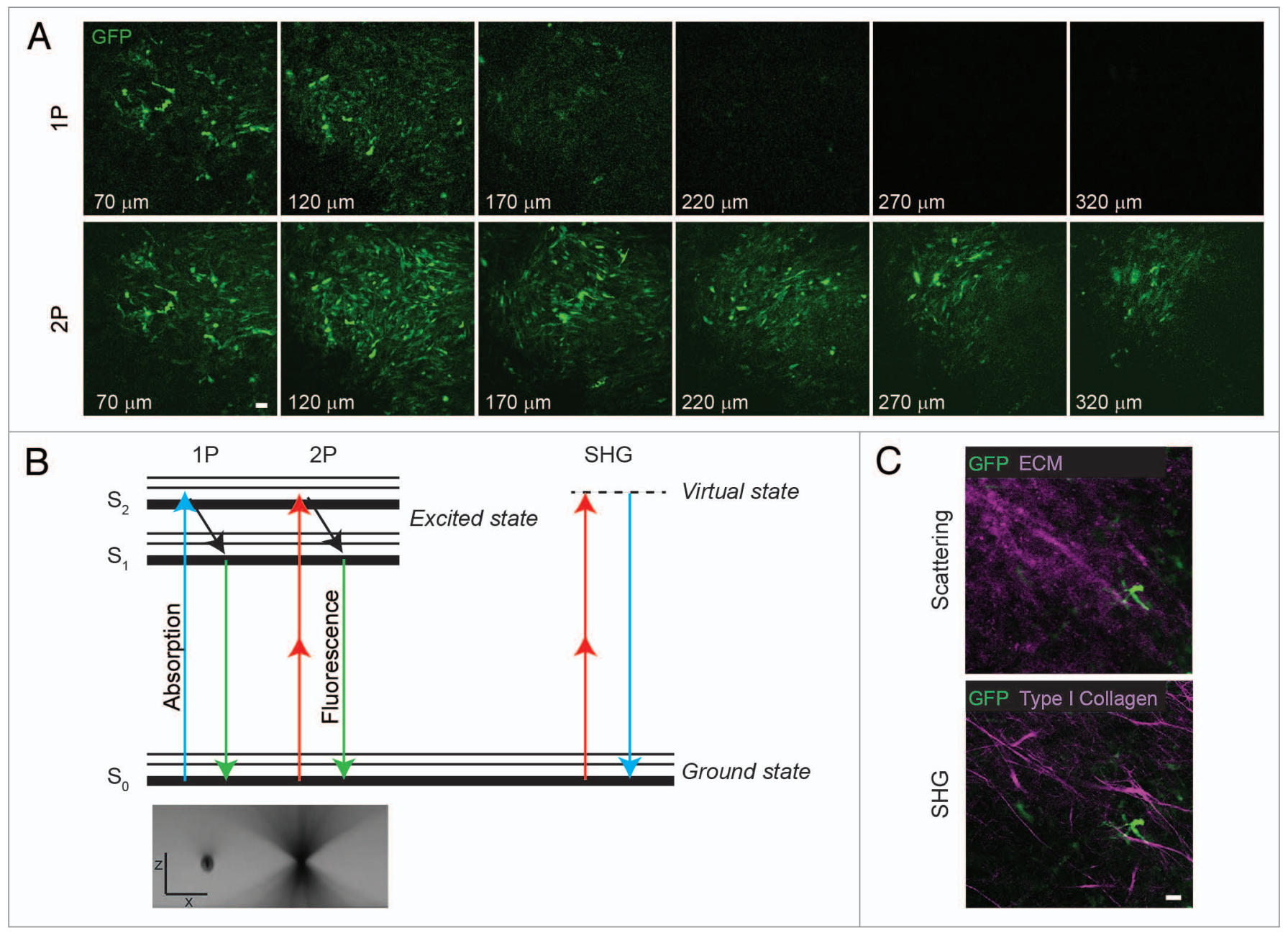

Figure 2. Single-photon microscopy versus two-photon microscopy. (A) A Z-stack of images of a mouse mammary tumor (KeP1_11 Dendra2) was acquired with single-photon (1P, confocal microscope) and two-photon (2P, two-photon microscope) excitation in a living mouse. The imaging depth is indicated in every image. Note that deep inside tissue good contrast can only be obtained when using a two-photon microscope. (B) Jablonski diagram showing single-photon and two-photon absorption and emission by a fluorophore. For second harmonic generation (SHG) imaging excitation does not take place; instead, two photons scatter simultaneously, thereby generating a single photon in the visible light range. Lower image; two focal points were bleached in a fluorescent plastic using single- (left) and two-photon (right) excitation. Bleaching profiles are shown in XZ. Note that single-photon excitation creates a cone-like structure, while two-photon excitation is restricted to the focal point. (C) Intravital images of the same region in which scatter- or SHG-signal from ECM fibers was acquired. Scale bar represents $20 \mu \mathrm{m}$.

already in $1931^{18}$ and validated in 1961)..$^{19}$ This technique, often referred to as two-photon microscopy, renders elimination of out-of-focus light by a pinhole redundant, since the excitatory photon density and thereby the two-photon excitation effect is strictly confined to the confocal plane (Fig. 2B). This simplifies the optical path, because emitted light does not have to travel back through the scanner with losses of light at the pinhole and mirrors, but instead can be detected close to the objective. ${ }^{20}$ The advantages of two-photon microscopy result in low bleaching and minimal phototoxicity deep inside living tissue.

To visualize individual cells within various organs of the mouse, the imaging depth of two-photon microscopy is not sufficient and requires surgical exposure of the imaging site. ${ }^{21}$ However, these surgical procedures limit the duration of imaging sessions to several hours. Long-term intravital imaging (up to $30 \mathrm{~h}$ ) of surgically exposed tumors in mice has been achieved by optimized imaging conditions (e.g., monitoring vitals). ${ }^{15,21}$ However, by using the dorsal skinfold chamber, Lehr and coworkers pioneered high-resolution intravital imaging over multiple days. ${ }^{22}$ At the present time, this chamber is widely used for multi-day imaging of the vasculature and tumors. ${ }^{23}$ More recently, other types of chambers have been developed by us and others to study mammary tissue, ${ }^{24,25}$ brain tissue ${ }^{26}$ and the spinal cord. ${ }^{27}$ Although imaging windows for the lung have been designed, they have not yet allowed imaging for more than a few hours. ${ }^{28}$

To monitor individual cells over multiple imaging sessions, vascular and extracellular matrix structures and tattooed reference marks have been used as roadmaps in healthy tissue in order to repeatedly trace back studied cells. ${ }^{29-31}$ In this manner, formation of metastasis has been followed for weeks (Ritsma L. and van Rheenen J., unpublished) with the animals well recovering from 
anesthesia in between the imaging sessions. If, however, tissue topology changes over time (e.g., in tumorigenic tissue), areas of interest can be retraced by taking advantage of photoconvertable fluorophores such as Dendra2 ${ }^{32}$ and PSmOrange. ${ }^{33}$ For example, violet illumination shifts the absorption and emission spectra of Dendra2 towards longer wavelengths converting green Dendra2 to red Dendra2 fluorophores. We have used Dendra2 to photomark and track individual cells and groups of cells for multiple days $^{34}$ (Fig. 3B) and could, thereby, visualize distinct migratory behavior of tumor cells. For example, we showed that tumor cells surrounding large blood vessels are more migratory than tumor cells surrounding capillaries. ${ }^{24}$ This assay has high potential to test the effects of clinically relevant pharmacological agents in vivo as was done for agents that target integrin-Fak-Src signaling. ${ }^{35}$ Thus, the combination of photoconvertable fluorophores and imaging windows provides a powerful tool for long-term intravital imaging at high resolution.

Taken together, we are now able to detect fluorescence at high resolution, deep inside living tissue and over multiple days. Therefore, it comes as no surprise that intravital imaging is becoming increasingly popular to study the behavior of fluorescently labeled cells in the in vivo setting and, as will be discussed below, signaling events between and within these cells.

\section{Signaling Events Between Cells}

In order to study signaling events between cells, multiple cell and/or tissue types must be visualized simultaneously. Contrast agents are often used to distinguish between different cell types and tissues. However, certain substances (such as ECM, blood vessel structures) are detectable without labeling. For example, optical frequency domain imaging (OFDI) detects the differential optical scattering properties of various tissue structures such as blood and lymphatic vessels and has (already) been used to study angiogenesis and lymphangiogenesis. ${ }^{36}$ As another example, reflectance imaging (also referred to as back-scattering) is based on the detection of excitation light that is scattered by solid-state structures resulting in contrast between dense and less dense tissue. ${ }^{37}$ Reflection of the excitation light occurs at the interface between structures with differential refractive indices such as ECM components and water (Fig. 2C). Although the signal is not specific, reflectance imaging can visualize many microenvironmental structures ranging from ECM or blood vessels to stromal cells (e.g., reviewed in refs. 37 and 38). A more specific and regularly used technique to visualize collagen fibers is second harmonic generation (SHG) microscopy (Fig. 2C). At highly ordered and non-centrosymmetric structures, such as Type I collagen, the energies of two photons are combined and reflected as a single photon with doubled energy and half the wavelength. Typical wavelengths used for SGH-imaging range between 800 and $1,300 \mathrm{~nm}$, since the SHG-signal can then be detected using standard fluorescence microscopy filter sets. Since SHG and reflectance imaging are not based on fluorescence phenomena, they do not excite molecules and therefore do not induce photobleaching. These techniques can be used to study Type
I collagen in various healthy and pathogenic tissues including skin, gut and breast (e.g., reviewed in ref. 39). For example, SHG has proven to be highly usefull when studying cancer cells; it has been shown that breast cancer cells migrate along collagen-I fibers with high velocity and persistence (Fig. 3A). ${ }^{1}$

Another way to visualize cells and tissues without labeling them is by detecting endogenous fluorescent molecules which are present in almost every cell type such as tryptophan, pyridinic and flavin co-enzymes; their emission is commonly referred to as autofluorescence (see e.g., reviewed in ref. 40). Since both excitation and emission spectra of these components have considerable overlap, the fluorescence level cannot be used to distinguish among cell types. However, the fluorescence lifetime (the average time an excited fluorophore resides in its excited state) does differ among the various components (e.g., tau-NADH $\sim 1$ ns and tauFAD $-3 \mathrm{~ns})^{41}$ and can thus be measured using FLIM (fluorescence lifetime imaging microscopy). The different molar ratios of these autofluorescent components, as present in distinct celltypes and tissues, will constitute cell type specific (average) autofluorescence lifetimes. Thus, imaging the (average) lifetime of auto-fluorescence has a strong potential for distinguishing multiple cell-types (Fig. 4A). This technique has already been successfully applied to discriminate healthy from tumor tissue $e^{42-44}$ and to predict tumor grade parameters, such as metastatic potential. ${ }^{45}$

As mentioned above, cell types and tissues can also be distinguished by using contrast agents. However, most contrast agents dilute quickly, for example due to cell division. When short term labeling is adequate, blood vessels can be visualized by angiography, i.e., injection of fluorescently labeled high-molecular weight dextran or quantum dots into the blood stream. As another example, intravenously injected low molecular weight-dextran molecules $(<70 \mathrm{kD})$ leak out of the blood into the surrounding tissue, where they are taken up by phagocytic immune cells such as macrophages. Moreover, dendritic cells can be labeled by intracutaneous injection of carboxy-fluorescein diacetate succinimidyl ester (CSFE). ${ }^{46}$ Immune cells can also be specifically labeled by transferring isolated cells into recipient mice after labeling them ex vivo with tracker dyes. ${ }^{47}$ A general drawback of the latter approach is that these labeled cells will only constitute a small fraction of the total blood cell population of the recipient animal. Alternatively, cell-type specific fluorescent antibodies (e.g., for lymphatics, see reviewed in ref. 48; for $\mathrm{Grl}^{+}$myeloid cells, see reviewed in ref. 15) can be injected to establish contrast between different cell types. Especially for immune cells that can be adoptively transferred, these approaches enable researchers to label differential cell types with specific colors and visualize their physical interactions in vivo (e.g., reviewed in ref. 49).

Since the introduction of genetically encoded fluorophores such as green fluorescent protein (GFP), it has become possible to label non-hematopoietic lineages that could not be adoptively transferred, such as cancer cells with an epithelial origin. For this, fluorescent protein (FP) expression, driven by cell-type specific promoters, has been the preferred method to visualize cell types in intravital imaging experiments. Advantages of these FPs are that they (1) are non toxic, (2) are not limited in tissue penetration (as labeled antibodies or dyes are) and (3) come into place 


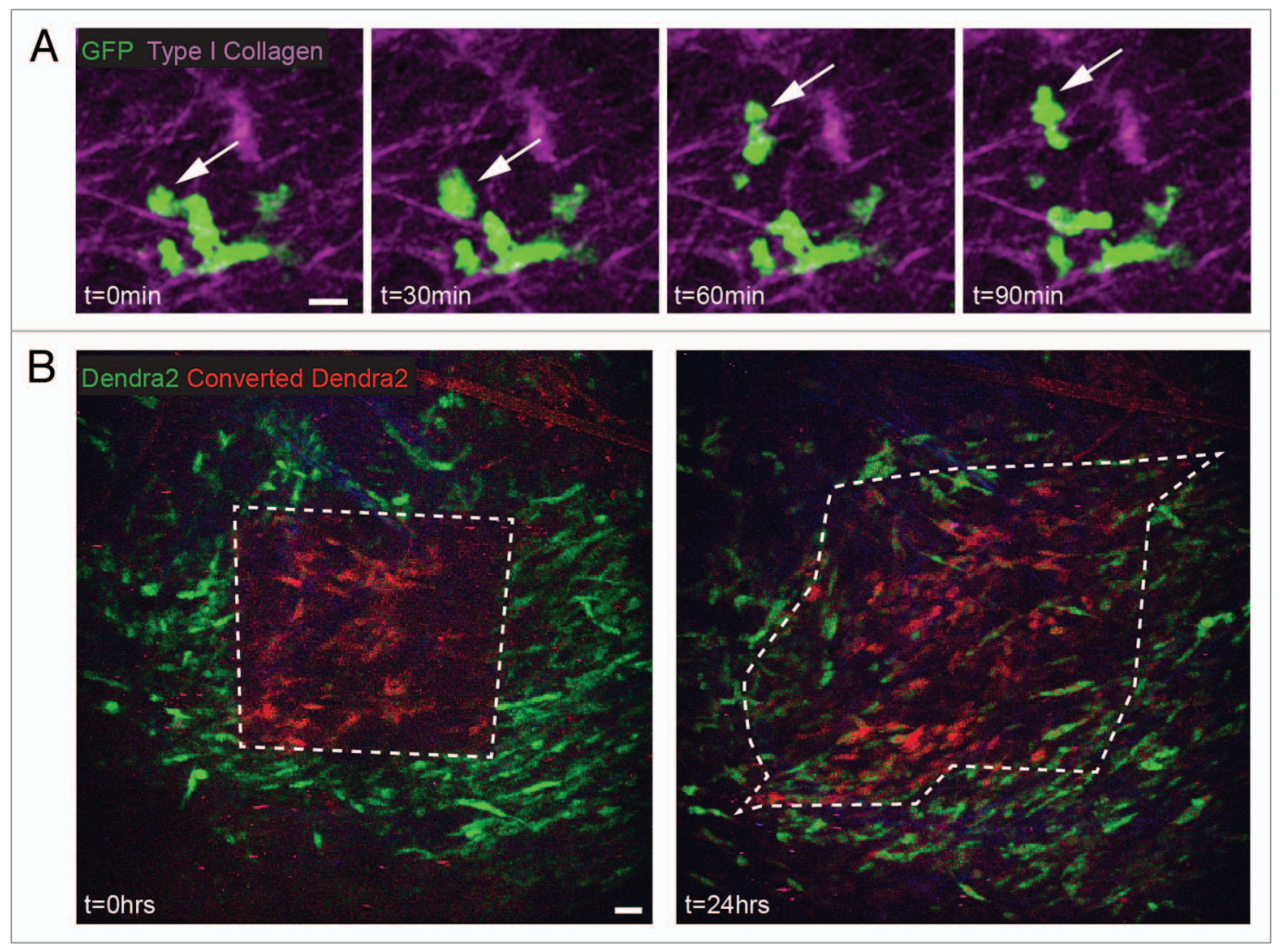

Figure 3. Visualizing cell migration over long and short periods of time. Intravital imaging of mouse tumor cells was performed using two-photon microscopy. (A) Stills of a time-series showing KeP1_11-Dendra2 cells migrating along type I collagen fibers. (B) C26-Dendra2 cells were imaged through a mammary imaging window after photomarking a subpopulation in a square region (dashed square) by violet light-induced photoconversion of Dendra2. Twenty-four hours later we rescanned the region. Note that the converted cell population has relocated (see dashed line). The scale bars represent $20 \mu \mathrm{m}$.

non-invasively. Thanks to a variety of FP color variants, multiple cell types can currently be genetically labeled and simultaneously visualized (e.g., blue, green and red fluorophores). This has led to the exciting possibility to study interactions and communication between different cell types in real time. For example, Egeblad and coworkers visualized the behavior of different stromal cells in mammary tumors and showed that most stromal cells exhibit higher motility at the tumor edge than when residing within the tumor mass. ${ }^{15}$ In another study, Wyckoff and colleagues visualized how signaling between mammary tumor cells and macrophages drive metastasis. ${ }^{50}$ By co-registration of GFPexpressing mammary tumor cells and Texas red-dextran labeled macrophages they showed how macrophages assist the tumor cells in invading the stroma and entering the blood stream. ${ }^{50}$ Macrophages were also found to be involved in the development of mycobacterial liver granulomas. ${ }^{51}$ In yet another study it was shown that $\mathrm{T}$ cell interactions with dendritic cells are governed by $\mathrm{T}$ cell sensing of the antigen dose, creating a threshold for its activation. ${ }^{52}$ Nowadays, many new fluorescent proteins with additional properties have been designed, opening new avenues for intravital imaging of cell-cell signaling. For example, fluorescent proteins like LSS-mKate1, ${ }^{53}$ have been designed for visualization in combination with CFP and GFP, since e.g., mKeima combines a CFP-like absorption spectrum with a mRFP-like emission spectrum. Piatkevich and co-workers used this multiple-channel approach to visualize that tumor cells are more polarized when they are in close proximity with blood vessels than when they are located far away from the circulation. ${ }^{53}$ Finally, far-red fluorescent proteins such as mNeptune, eqFP650/670 and iRFP have been developed to allow imaging deep inside tissue, thanks to their excitation and emission spectrum that are near-infrared. ${ }^{54-56}$ For a good review on the latest developments of fluorescent proteins see reference 57 .

\section{Signaling Events Inside Cells}

The dynamic interplay between inter- and intra-cellular signaling leads to heterogeneous and changing expression profiles and differentiation states. Intravital imaging of FPs in which the expression is driven by differentiation promoters are strong tools to visualize these dynamic and diverse cellular states. For example, Pinner and colleagues monitored GFP expression driven by the Brn-2 promoter to visualize the differentiation status of metastasizing melanoma cells. This revealed the switching from a non-differentiated to a more differentiated state of cells that exit the primary tumor and enter the secondary site. ${ }^{58}$ The 


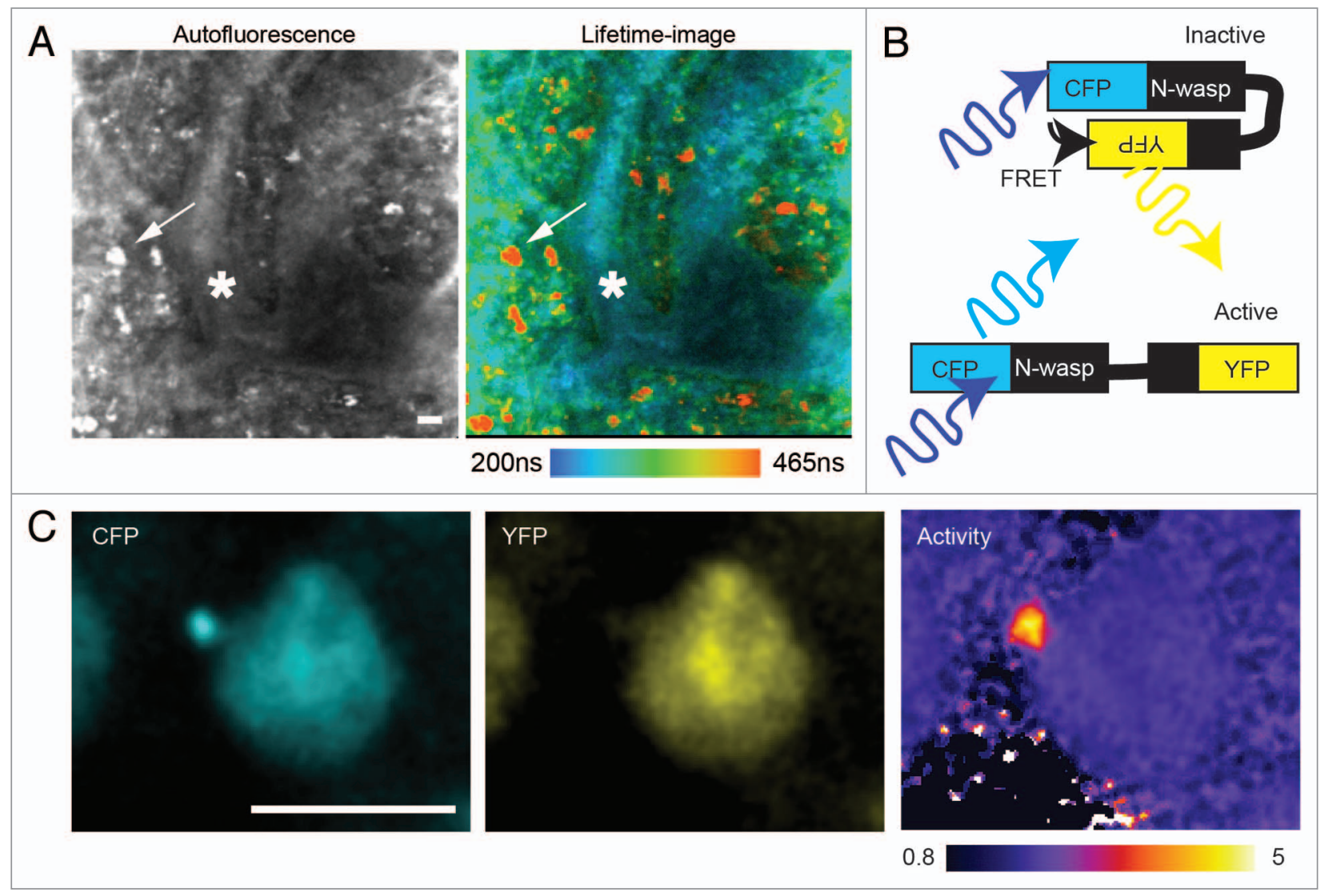

Figure 4. FLIM and FRET measurements in a living mouse. (A) Discriminative visualization of multiple tissue components by Fluorescence Lifetime Imaging Microscopy (FLIM). Shown are the autofluorescence and lifetime image. Note that blood vessel (e.g., asterisk) and cells (e.g., arrow) have distinct average lifetimes. (B) Cartoon of the N-Wasp FRET biosensor. In its inactive form, the CFP- and YFP-moieties are in close proximity so that FRET can occur upon CFP excitation, resulting in YFP $(\sim 540 \mathrm{~nm})$ emission. When the N-Wasp sensor core is activated, the sensor will unfold, leading to a loss of energy transfer. This is reflected as increased CFP and decreased YFP emission. (C) Ratiometric FRET imaging performed on MTLn3 mammary tumor expressing the N-Wasp FRET biosensor. CFP excitation induces CFP (left part) and YFP emission (middle part); the FRET ratio image (CFP/YFP, right part) reflects $\mathrm{N}$-Wasp activity. Note the small membrane protrusion in which $\mathrm{N}$-Wasp is active. Scale bar represents $10 \mu \mathrm{m}$.

differentiated status of cells is tightly regulated by intracellular concentration and spatio-temporal distribution of second messengers, proteins and their activities. Fluorescently tagged fusion proteins have been extensively used to determine protein localization in vitro as a readout for cell signaling status. An increasing number of research groups have also adopted fusion proteins for in vivo studies. For example, fluorescently tagged proteins have been used to monitor cell cycle and autophagy. ${ }^{59,60}$ Furthermore, FP-tagged receptors have been monitored to study their in vivo activation, clustering and internalization (e.g., T-cell receptor activation).$^{61}$ For the visualization of downstream signaling pathways, FP-tagged versions of the adhesion molecule E-cadherin ${ }^{62}$ and actin- and myosin-binding proteins ${ }^{63,64}$ have been used, amongst others. Since the application of FP-tagged proteins is widespread, we expect that this list only represents the beginning of what the future will bring.

In addition to localization of FP-tagged molecules, the levels of second messengers and protein activities can be monitored in vivo. For this, numerous fluorescence-based biosensors have been generated. Biosensors generally contain a target sensing platform (an enzyme substrate or a small molecule-binding peptide) fused to a fluorescent biomolecule (antibody, synthetic dye or fluorescent protein). Various fluorescent biosensors are based on dynamically changing fluorescent properties or localization of the probe. Examples are Fluo-3, which acquires fluorescent signal upon binding of calcium, ${ }^{65}$ and the cathepsin activity-based probe, which binds covalently and irreversibly to cathepsin proteases. ${ }^{66}$ Biosensors containing fluorescent proteins are often based on a change in fluorescent resonance energy transfer (FRET). FRET is the process by which energy from an excited donor fluorophore is transferred to an acceptor fluorophore through radiationless dipole-dipole coupling. ${ }^{67}$ The efficiency of this energy transfer is highly dependent on the distance between (e.g., $<10 \mathrm{~nm}$ for CFP/YFP) and the relative orientation of donor and acceptor fluorophore (e.g., reviewed in ref. 67). Most FRETbased biosensors are based on a change in the orientation and/or the distance between the donor and acceptor fluorophore.

FRET-biosensors can be subdivided in three categories; ligand-, affinity- or activity-based sensors. Ligand-based sensors are based on the binding of a ligand or a protein to the FRETbiosenor leading to a change in the relative orientation and/or distance between the donor and acceptor fluorophore. These 
biosensors are employed to reflect second messengers levels (e.g., cAMP, $\mathrm{Ca}^{2+}$ and $\mathrm{PIP}_{2}$ ) or protein-protein interactions and have been used successfully to study for example $\mathrm{Ca}^{2+}$ transients in the living mouse. ${ }^{68}$ Affinity-based sensors recognize specific conformations or activation status of the target. For instance, the inactive-to-active conformational change of the $\mathrm{N}$-Wasp results in a decrease in FRET (Fig. 4B). ${ }^{69}$ Intravital FRET imaging of mammary tumor cells that express this sensor suggests that N-Wasp can be locally activated in cell protrusions (Fig. 4C). Indeed, a detailed intravital imaging study by Gligorijevic and coworkers showed that downregulation of N-Wasp activity resulted in a reduced number of protrusions that degrade ECM and further resulted in less metastasis. ${ }^{70}$ Other FRET probes that have been used to visualize signaling activity with subcellular resolution include the RhoA biosensor. ${ }^{71}$

In activity-based FRET sensors, the sensing platform is an enzyme substrate that responds to an enzymatic activity, such as phosphorylation, methylation or proteolytic cleavage. In case of the caspase-3 FRET biosensor, endogenous caspase-3 enzymes recognize and cleave the DVED recognition sequence that is located in between CFP and YFP, inducing a reduction in FRET. This sensor has been used successfully to monitor caspase3 -mediated apoptosis in keratinocytes and tumor cells in living mice. ${ }^{30,72}$ For instance, Breart and colleagues used this biosensor to visualize that cytotoxic T lymphocytes (CTLs) kill one tumor cell every 6 hours, ${ }^{73}$ illustrating the strength of the in vivo visualization of cell signaling.

\section{Future Perspectives}

High-resolution intravital imaging employs advanced microscopy to study in vivo processes at a single cell resolution. In the last decade this technique has become increasingly popular to study and validate cell signaling processes that had previously been studied in in vitro systems, or that were simply impossible to study. The discovery of genetically encoded proteins enabled researchers to label tissue-specific cells and to visualize proteins and signaling processes (by using biosensors). Contrast agents can be employed to further distinguish tissues and advanced imaging techniques such as FLIM, FRET and SHG help to visualize various tissue components and cell signaling processes. In the near future, other microscopic techniques that are already employed in in vitro biological studies, are likely to be introduced for intravital microscopy as well. For example, a common technique to study the dynamics of signaling events in (living) cultured cells is fluorescence recovery after photobleaching (FRAP). ${ }^{74}$ FRAP makes use of the relatively quick bleaching properties of fluorescent proteins. Upon photobleaching the FPs in a well-defined area, the fluorescence recovery in that area reflects the exchange of bleached with non-bleached FPs and therefore constitutes a measure for the protein's diffusion rate. Although FRAP is a widely used technique in 2D-culture models, few laboratories apply it in vivo. However, intravital FRAP imaging can be extremely powerful as illustrated by Serrels and co-workers, who studied the trafficking of E-cadherin in mouse tumors cells. In their elegant study, they used FRAP to show that
E-cadherin trafficking occurs at significantly faster rates in living mice than in cultured cells. ${ }^{62}$ In addition to FRAP, Fluorescence Correlation Spectroscopy (FCS) can also be employed to unravel protein interactions as well as protein diffusion. FCS is a technique which measures protein diffusion by autocorrelating temporal fluctuations of a fluorescent signal (from a tagged molecule) within a small, stationary focal volume $\left(\sim 1 \mu \mathrm{m}^{3}\right)$. It requires low concentrations of fluorescent molecules and is therefore particularly powerful when the fluorescence signal is low. A variant of FCS is fluorescence cross-correlation spectroscopy (FCCS). Cross-correlation of multiple fluctuation signals in more than one spectral channel allows one to quantify protein interactions and enzyme activities. However, due to light scattering of thick tissues, this technique is not yet commonly applied in mice.

In order to advance intravital imaging as an experimental technique in the coming years, it will be of paramount importance to develop technical means to genetically manipulate individual cells in living mice. Recent developments in this direction include cell lines in which cancer cell behavior can be manipulated by the inducible expression of oncogenes or signaling proteins. ${ }^{75}$ Furthermore, developments in photo-manipulation such as laser-induced activation of caged proteins and caged compounds (NPE-caged cAMP), proteins ( Rac1 ${ }^{76}$ and cofilin $^{77}$ ) and gene expression ${ }^{78}$ will further expand the toolkit to manipulate signaling pathways in time and space. Developing the photo-inducible activitation of the Cre recombinase in vivo will be of particular interest ${ }^{79}$ since it can be combined with the extensive and already widely available part of mouse models in which this recombinase can activate or deplete genes or FPs. Interestingly, the lab of Vriz showed the proof-of-principle experiment in zebrafish embryos by locally photo-releasing caged-cyclofen, resulting in localized CreERT2 activity and the subsequent localized induction of YFP expression. ${ }^{80}$

Taken together, we can conclude that intravital imaging is an exciting new technique, that allows researchers to study cell behavior and even signaling events by applying biosensors in an in vivo setting. This relatively new field is open to many groundbreaking advances in the near future, so we can look forward to an exciting era in which intravital imaging will provide new insights into in vivo cellular signaling.

\section{Disclosure of Potential Conflicts of Interest}

No potential conflicts of interest were disclosed.

\section{Acknowledgments}

We would like to thank our colleagues for stimulating discussions and A. de Graaff of the Hubrecht Imaging Center for imaging support. We thank the lab of John Condeelis for providing Figure 4C which was supported by the NIH grant CA100324. This work was supported by a VIDI fellowship (91710330) and an equipment grants (175.010.2007.007 and 834.11.002) from the Dutch Organization of Scientific Research (NWO), and a research grant from the Dutch Cancer Society (KWF) (HUBR 2009-4621). We apologize for references omitted due to space limitation. 


\section{References}

1. Condeelis J, Segall JE. Intravital imaging of cell movement in tumours. Nat Rev Cancer 2003; 3:921-30; PMID:14737122; http://dx.doi.org/10.1038/nrc1231.

2. Beerling E, Ritsma L, Vrisekoop N, Derksen PWB, van Rheenen J. Intravital microscopy: new insights into metastasis of tumors. J Cell Sci 2011; 124:299310; PMID:21242309; http://dx.doi.org/10.1242/ jcs.072728.

3. Zomer A, Beerling E, Vlug EJ, van Rheenen J. Realtime intravital imaging of cancer models. Clin Transl Oncol 2011; 13:848-54; PMID:22126727; http:// dx.doi.org/10.1007/s12094-011-0745-3.

4. Pittet MJ, Weissleder R. Intravital imaging. Cell 2011; 147:983-91; PMID:22118457; http://dx.doi. org/10.1016/j.cell.2011.11.004.

5. Wagner R. Erlauterungstaflen zur physiologie und entwicklungsgeschichte. Leipzig, Germany; Leopold Voss 1839.

6. Heimstadt O. Das Fluoreszenzmikroskop. Z Wiss Mikrosk 1911; 28:330-7.

7. Haitinger M. Fluoreszenz-Mikroskopie. 2 Erweiterte Auflage. Leipzig: Akademische Verlagsgesellschaft 1959.

8. Ellinger P, Hirt A. Mikroskopische Beobachtungen an lebenden Organen mit Demonstrationen (Intravitalmikroskopie). Naunyn Schmiedebergs Arch Pharmacol 1929; 147:63; http://dx.doi.org/10.1007/ BF01946036.

9. Singer E. A Microscope for Observation of Fluorescence in Living Tissues. Science 1932; 75:28991; PMID:17811776; http://dx.doi.org/10.1126/ science.75.1941.289-a.

10. Chambers AF, Schmidt EE, MacDonald IC, Morris VL, Groom AC. Early steps in hematogenous metastasis of B16F1 melanoma cells in chick embryos studied by high-resolution intravital videomicroscopy. J Natl Cancer Inst 1992; 84:797-803; PMID:1573668; http://dx.doi.org/10.1093/jnci/84.10.797.

11. von Andrian UH. Intravital microscopy of the peripheral lymph node microcirculation in mice. Microcirculation 1996; 3:287-300; PMID:8930886; http://dx.doi.org/10.3109/10739689609148303.

12. White JG, Amos WB, Fordham M. An evaluation of confocal versus conventional imaging of biological structures by fluorescence light microscopy. J Cell Biol 1987; 105:41-8; PMID:3112165; http://dx.doi. org/10.1083/jcb.105.1.41.

13. van Meer G, Stelzer EH, Wijnaendts-van-Resandt RW, Simons K. Sorting of sphingolipids in epithelial (Madin-Darby canine kidney) cells. J Cell Biol 1987; 105:1623-35; PMID:3667693; http://dx.doi. org/10.1083/jcb.105.4.1623.

14. Farina KL, Wyckoff JB, Rivera J, Lee H, Segall JE, Condeelis JS, et al. Cell motility of tumor cells visualized in living intact primary tumors using green fluorescent protein. Cancer Res 1998; 58:2528-32; PMID:9635573.

15. Egeblad M, Ewald AJ, Askautrud HA, Truitt ML, Welm BE, Bainbridge E, et al. Visualizing stromal cell dynamics in different tumor microenvironments by spinning disk confocal microscopy. Dis Model Mech 2008; 1:155-67; PMID:19048079; http://dx.doi. org/10.1242/dmm.000596.

16. Helmchen F, Denk W. Deep tissue two-photon microscopy. Nat Methods 2005; 2:932-40; PMID:16299478; http://dx.doi.org/10.1038/nmeth818.

17. Denk W, Strickler JH, Webb WW. Two-photon laser scanning fluorescence microscopy. Science 1990; 248:73-6; PMID:2321027; http://dx.doi.org/10.1126/ science. 2321027.

18. Goppert-Mayer M. Uber Elementarakte mit zwei quantensprungen. Ann phys 1931; 9:273-94.

19. Kaiser W, Garrett CGB. Two-Photon Excitation in $\mathrm{CaF}_{2}: \mathrm{Eu2}_{2}$. Phys Rev Lett 1961; 7:229; http://dx.doi. org/10.1103/PhysRevLett.7.229.
20. Centonze VE, White JG. Multiphoton excitation provides optical sections from deeper within scattering specimens than confocal imaging. Biophys 1998; 75:2015-24; PMID:9746543; http://dx.doi. org/10.1016/S0006-3495(98)77643-X.

21. Ewald AJ, Werb Z, Egeblad M. Preparation of mice for long-term intravital imaging of the mammary gland. Cold Spring Harb Protoc 2011; 2011:5562; PMID:21285262; http://dx.doi.org/10.1101/pdb. prot 5562.

22. Lehr HA, Leunig M, Menger MD, Nolte D, Messmer K. Dorsal skinfold chamber technique for intravital microscopy in nude mice. Am J Pathol 1993; 143:1055-62; PMID:7692730.

23. Brown EB, Campbell RB, Tsuzuki Y, Xu L, Carmeliet P, Fukumura D, et al. In vivo measurement of gene expression, angiogenesis and physiological function in tumors using multiphoton laser scanning microscopy. Nat Med 2001; 7:864-8; PMID:11433354; http:// dx.doi.org/10.1038/89997.

24. Kedrin D, Gligorijevic B, Wyckoff J, Verkhusha VV, Condeelis J, Segall JE, et al. Intravital imaging of metastatic behavior through a mammary imaging window. Nat Methods 2008; 5:1019-21; PMID:18997781; http://dx.doi.org/10.1038/nmeth.1269.

25. Shan S, Sorg B, Dewhirst MW. A novel rodent mammary window of orthotopic breast cancer for intravital microscopy. Microvasc Res 2003; 65:109-17; PMID:12686168; http://dx.doi.org/10.1016/S00262862(02)00017-1.

26. Yuan F, Salehi HA, Boucher Y, Vasthare US, Tuma RF, Jain RK. Vascular permeability and microcirculation of gliomas and mammary carcinomas transplanted in rat and mouse cranial windows. Cancer Res 1994; 54:4564-8; PMID:8062241.

27. Farrar MJ, Bernstein IM, Schlafer DH, Cleland TA, Fetcho JR, Schaffer CB. Chronic in vivo imaging in the mouse spinal cord using an implanted chamber. Nat Methods 2012; 9:297-302; PMID:22266542; http:// dx.doi.org/10.1038/nmeth.1856.

28. Looney MR, Thornton EE, Sen D, Lamm WJ, Glenny RW, Krummel MF. Stabilized imaging of immune surveillance in the mouse lung. Nat Methods 2011; 8:91-6; PMID:21151136; http://dx.doi.org/10.1038/ nmeth.1543.

29. Yang M, Baranov E, Wang JW, Jiang P, Wang X, Sun FX, et al. Direct external imaging of nascent cancer, tumor progression, angiogenesis and metastasis on internal organs in the fluorescent orthotopic model. Proc Nat Acad Sci USA 2002; 99:3824-9; PMID:11891294; http://dx.doi.org/10.1073/pnas.052029099.

30. Bins AD, van Rheenen J, Jalink K, Halstead JR, Divecha N, Spencer DM, et al. Intravital imaging of fluorescent markers and FRET probes by DNA tattooing. BMC Biotechnol 2007; 7:2; PMID:17201912; http://dx.doi.org/10.1186/1472-6750-7-2.

31. Perentes JY, McKee TD, Ley CD, Mathiew H, Dawson M, Padera TP, et al. In vivo imaging of extracellular matrix remodeling by tumor-associated fibroblasts. Nat Methods 2009; 6:143-5; PMID:19151720; http:// dx.doi.org/10.1038/nmeth.1295.

32. Gurskaya NG, Verkhusha VV, Shcheglov AS, Staroverov DB, Chepurnykh TV, Fradkov AF, et al. Engineering of a monomeric green-to-red photoactivatable fluorescent protein induced by blue light. Nat Biotechnol 2006; 24:461-5; PMID:16550175; http:// dx.doi.org/10.1038/nbt1191.

33. Subach OM, Patterson GH, Ting LM, Wang Y, Condeelis JS, Verkhusha VV. A photoswitchable orange-to-far-red fluorescent protein, PSmOrange. Nat Methods 2011; 8:771-7; PMID:21804536; http:// dx.doi.org/10.1038/nmeth.1664.

34. Gligorijevic B, Kedrin D, Segall JE, Condeelis J, van Rheenen J. Dendra2 photoswitching through the Mammary Imaging Window. J Vis Exp 2009; 28:1278; PMID:19578330
35. Canel M, Serrels A, Miller D, Timpson P, Serrels B, Frame MC, et al. Quantitative in vivo imaging of the effects of inhibiting integrin signaling via Src and FAK on cancer cell movement: effects on E-cadherin dynamics. Cancer Res 2010; 70:9413-22; PMID:21045155; http://dx.doi.org/10.1158/0008-5472.CAN-10-1454.

36. Vakoc BJ, Lanning RM, Tyrrell JA, Padera TP, Bartlet LA, Stylianopoulos T, et al. Three-dimensional microscopy of the tumor microenvironment in vivo using optical frequency domain imaging. Nat Med 2009; 15:1219-23; PMID:19749772; http://dx.doi. org/10.1038/nm. 1971.

37. Friedl P, Maaser K, Klein CE, Niggemann B, Krohne G, Zänker KS. Migration of highly aggressive MV3 melanoma cells in 3-dimensional collagen lattices results in local matrix reorganization and shedding of alpha2 and beta 1 integrins and CD44. Cancer Res 1997; 57:2061-70; PMID:9158006.

38. Sahai E. Illuminating the metastatic process. Nat Rev Cancer 2007; 7:737-49; PMID:17891189; http:// dx.doi.org/10.1038/nrc2229.

39. Wolf K, Alexander S, Schacht V, Coussens LM, von Andrian UH, van Rheenen J, et al. Collagen-based cell migration models in vitro and in vivo. Semin Cell Dev Biol 2009; 20:931-41; PMID:19682592; http:// dx.doi.org/10.1016/j.semcdb.2009.08.005.

40. Zipfel WR, Williams RM, Christie R, Nikitin AY, Hyman BT, Webb WW. Live tissue intrinsic emission microscopy using multiphoton-excited native fluorescence and second harmonic generation. Proc Natl Acad Sci USA 2003; 100:7075-80; PMID:12756303; http:// dx.doi.org/10.1073/pnas.0832308100.

41. Skala MC, Riching KM, Gendron-Fitzpatrick A Eickhoff J, Eliceiri KW, White JG, et al. In vivo multiphoton microscopy of $\mathrm{NADH}$ and FAD redox states, fluorescence lifetimes and cellular morphology in precancerous epithelia. Proc Natl Acad Sci USA 2007; 104:19494-9; PMID:18042710; http://dx.doi. org/10.1073/pnas.0708425104

42. Sun Y, Phipps J, Elson DS, Stoy H, Tinling S, Meier $\mathrm{J}$, et al. Fluorescence lifetime imaging microscopy: in vivo application to diagnosis of oral carcinoma. Opt Lett 2009; 34:2081-3; PMID:19572006; http:// dx.doi.org/10.1364/OL.34.002081.

43. Cicchi R, Sestini S, De Giorgi V, Massi D, Lotti T, Pavone FS. Nonlinear laser imaging of skin lesions. J Biophotonics 2008; 1:62-73; PMID:19343636; http:// dx.doi.org/10.1002/jbio.200710003.

44. Provenzano PP, Eliceiri KW, Keely PJ. Multiphoton microscopy and fluorescence lifetime imaging microscopy (FLIM) to monitor metastasis and the tumor microenvironment. Clin Exp Metastasis 2009; 26:35770; PMID:18766302; http://dx.doi.org/10.1007/ s10585-008-9204-0.

45. Conklin MW, Provenzano PP, Eliceiri KW, Sullivan R, Keely PJ. Fluorescence lifetime imaging of endogenous fluorophores in histopathology sections reveals differences between normal and tumor epithelium in carcinoma in situ of the breast. Cell Biochem Biophys 2009; 53:145-57; PMID:19259625; http://dx.doi. org/10.1007/s12013-009-9046-7.

46. Miller MJ, Hejazi AS, Wei SH, Cahalan MD, Parker I $T$ cell repertoire scanning is promoted by dynamic dendritic cell behavior and random $\mathrm{T}$ cell motility in the lymph node. Proc Natl Acad Sci USA 2004; 101:9981003; PMID:14722354; http://dx.doi.org/10.1073/ pnas.0306407101.

47. Miller MJ, Safrina O, Parker I, Cahalan MD. Imaging the single cell dynamics of $\mathrm{CD}^{+}{ }^{+} \mathrm{T}$ cell activation by dendritic cells in lymph nodes. J Exp Med 2004; 200:847-56; PMID:15466619; http://dx.doi. org/10.1084/jem.20041236

48. McElroy M, Bouvet M, Hoffman RM. Chapter 2 Color-Coded Fluorescent Mouse Models of Cancer Cell Interactions with Blood Vessels and Lymphatics. Methods in Enzymology: Academic Press 2008; 27-52. 
49. Mempel TR, Pittet MJ, Khazaie K, Weninger W, Weissleder $\mathrm{R}$, von Boehmer $\mathrm{H}$, et al. Regulatory $\mathrm{T}$ cells reversibly suppress cytotoxic $\mathrm{T}$ cell function independent of effector differentiation. Immunity 2006; 25:129-41; PMID:16860762; http://dx.doi. org/10.1016/j.immuni.2006.04.015.

50. Wyckoff JB, Wang Y, Lin EY, Li JF, Goswami S, Stanley ER, et al. Direct visualization of macrophage-assisted tumor cell intravasation in mammary tumors. Cancer Res 2007; 67:2649-56; PMID:17363585; http:// dx.doi.org/10.1158/0008-5472.CAN-06-1823.

51. Egen JG, Rothfuchs AG, Feng CG, Winter N, Sher A, Germain RN. Macrophage and $\mathrm{T}$ cell dynamics during the development and disintegration of mycobacterial granulomas. Immunity 2008; 28:271-84 PMID:18261937; http://dx.doi.org/10.1016/j.immuni.2007.12.010.

52. Henrickson SE, Mempel TR, Mazo IB, Liu B, Artyomov MN, Zheng $\mathrm{H}$, et al. $\mathrm{T}$ cell sensing of antigen dose governs interactive behavior with dendritic cells and sets a threshold for T cell activation. Nat Immunol 2008; 9:282-91; PMID:18204450; http:// dx.doi.org/10.1038/ni1559.

53. Piatkevich KD, Hulit J, Subach OM, Wu B, Abdulla A, Segall JE, et al. Monomeric red fluorescent proteins with a large Stokes shift. Proc Natl Acad Sci USA 2010; 107:5369-74; PMID:20212155; http://dx.doi. org/10.1073/pnas.0914365107.

54. Lin MZ, McKeown MR, Ng HL, Aguilera TA, Shaner NC, Campbell RE, et al. Autofluorescent proteins with excitation in the optical window for intravital imaging in mammals. Chem Biol 2009; 16:1169-79; PMID:19942140; http://dx.doi.org/10.1016/j.chembiol.2009.10.009.

55. Shcherbo D, Shemiakina II, Ryabova AV, Luker KE, Schmidt BT, Souslova EA, et al. Near-infrared fluorescent proteins. Nat Methods 2010; 7:8279; PMID:20818379; http://dx.doi.org/10.1038/ nmeth. 1501.

56. Filonov GS, Piatkevich KD, Ting LM, Zhang J, Kim $\mathrm{K}$, Verkhusha VV. Bright and stable near-infrared fluorescent protein for in vivo imaging. Nat Biotechnol 2011; 29:757-61; PMID:21765402; http://dx.doi. org/10.1038/nbt.1918.

57. Chudakov DM, Matz MV, Lukyanov S, Lukyanov KA. Fluorescent proteins and their applications in imaging living cells and tissues. Physiol Rev 2010; 90:1103-63; PMID:20664080; http://dx.doi.org/10.1152/physrev.00038.2009.

58. Pinner S, Jordan P, Sharrock K, Bazley L, Collinson $\mathrm{L}$, Marais R, et al. Intravital imaging reveals transient changes in pigment production and Brn2 expression during metastatic melanoma dissemination. Cancer Res 2009; 69:7969-77; PMID:19826052; http://dx.doi. org/10.1158/0008-5472.CAN-09-0781.

59. Orth JD, Kohler RH, Foijer F, Sorger PK, Weissleder R, Mitchison TJ. Analysis of mitosis and antimitotic drug responses in tumors by in vivo microscopy and single-cell pharmacodynamics. Cancer Res 2011; 71:4608-16; PMID:21712408; http://dx.doi. org/10.1158/0008-5472.CAN-11-0412.
60. Tian F, Deguchi K, Yamashita T, Ohta Y, Morimoto $\mathrm{N}$, Shang J, et al. In vivo imaging of autophagy in a mouse stroke model. Autophagy 2010; 6:110714; PMID:20930570; http://dx.doi.org/10.4161/ auto.6.8.13427.

61. Friedman RS, Beemiller P, Sorensen CM, Jacobelli J, Krummel MF. Real-time analysis of T cell receptors in naive cells in vitro and in vivo reveals flexibility in synapse and signaling dynamics. J Exp Med 2010; 207:2733-49; PMID:21041455; http://dx.doi. org/10.1084/jem.20091201.

62. Serrels A, Timpson P, Canel M, Schwarz JP, Carragher $\mathrm{NO}$, Frame MC, et al. Real-time study of E-cadherin and membrane dynamics in living animals: implications for disease modeling and drug development. Cancer Res 2009; 69:2714-9; PMID:19318551; http://dx.doi.org/10.1158/0008-5472.CAN-08-4308.

63. Philippar U, Roussos ET, Oser M, Yamaguchi H, Kim HD, Giampieri S, et al. A Mena invasion isoform potentiates EGF-induced carcinoma cell invasion and metastasis. Dev Cell 2008; 15:813-28; PMID:19081071; http://dx.doi.org/10.1016/j.devcel.2008.09.003.

64. Wyckoff JB, Pinner SE, Gschmeissner S, Condeelis JS, Sahai E. ROCK- and myosin-dependent matrix deformation enables protease-independent tumorcell invasion in vivo. Curr Biol 2006; 16:1515-23 PMID:16890527; http://dx.doi.org/10.1016/j. cub.2006.05.065

65. Kao JP, Harootunian AT, Tsien RY. Photochemically generated cytosolic calcium pulses and their detec tion by fluo-3. J Biol Chem 1989; 264:8179-84 PMID:2498309.

66. Greenbaum D, Baruch A, Hayrapetian L, Darula Z, Burlingame A, Medzihradszky KF, et al. Chemical approaches for functionally probing the proteome. Mol Cell Proteomics 2002; 1:60-8; PMID:12096141 http://dx.doi.org/10.1074/mcp.T100003-MCP200.

67. Lakowicz JR. Principles of Fluorescence Spectroscopy. Springer 1999.

68. Mank M, Santos AF, Direnberger S, Mrsic-Flogel TD, Hofer SB, Stein V, et al. A genetically encoded calcium indicator for chronic in vivo two-photon imaging. Nat Methods 2008; 5:805-11; PMID:19160515; http:// dx.doi.org/10.1038/nmeth.1243.

69. Lorenz M, Yamaguchi H, Wang Y, Singer RH, Condeelis J. Imaging sites of $\mathrm{N}$-wasp activity in lamellipodia and invadopodia of carcinoma cells. Curr Bio 2004; 14:697-703; PMID:15084285; http://dx.doi. org/10.1016/j.cub.2004.04.008.

70. Gligorijevic B, Wyckoff J, Yamaguchi H, Wang Y, Roussos ET, Condeelis J. N-WASP-mediated invadopodium formation is involved in intravasation and lung metastasis of mammary tumors. J Cell Sci 2012; 125:724-34; PMID:22389406; http://dx.doi. org/10.1242/jcs. 092726
71. Timpson P, McGhee EJ, Morton JP, von Kriegsheim A, Schwarz JP, Karim SA, et al. Spatial regulation of RhoA activity during pancreatic cancer cell invasion driven by mutant p53. Cancer Res 2011; 71:747-57; PMID:21266354; http://dx.doi.org/10.1158/00085472.CAN-10-2267.

72. Keese M, Yagublu V, Schwenke K, Post S, Bastiaens P. Fluorescence lifetime imaging microscopy of chemotherapy-induced apoptosis resistance in a syngenic mouse tumor model. Int J Cancer 2010; 126:10413; PMID:19588498; http://dx.doi.org/10.1002/ ijc. 24730 .

73. Breart B, Lemaître F, Celli S, Bousso P. Two-photon imaging of intratumoral CD8 ${ }^{+} \mathrm{T}$ cell cytotoxic activity during adoptive $\mathrm{T}$ cell therapy in mice. J Clin Invest 2008; 118:1390-7; PMID:18357341; http://dx.doi. org/10.1172/JCI34388.

74. Edidin M, Zagyansky Y, Lardner TJ. Measurement of membrane protein lateral diffusion in single cells. Science 1976; 191:466-8; PMID:1246629; http:// dx.doi.org/10.1126/science.1246629.

75. Le Dévédec SE, Lalai R, Pont $\mathrm{C}$, de Bont $\mathrm{H}$, van de Water B. Two-photon intravital multicolor imaging combined with inducible gene expression to distinguish metastatic behavior of breast cancer cells in vivo. Mol Imaging Biol 2011; 13:67-77; PMID:20396956; http://dx.doi.org/10.1007/s11307-010-0307-z.

76. Wu YI, Frey D, Lungu OI, Jaehrig A, Schlichting I, Kuhlman B, et al. A genetically encoded photoactivatable Rac controls the motility of living cells. Nature 2009; 461:104-8; PMID:19693014; http://dx.doi. org/10.1038/nature08241

77. Ghosh M, Song X, Mouneimne G, Sidani M, Lawrence DS, Condeelis JS. Cofilin promotes actin polymerization and defines the direction of cell motility. Science 2004; 304:743-6; PMID:15118165; http://dx.doi. org/10.1126/science.1094561.

78. Wang X, Chen X, Yang Y. Spatiotemporal control of gene expression by a light-switchable transgene system. Nat Methods 2012; 9:266-9; PMID:22327833; http:// dx.doi.org/10.1038/nmeth.1892.

79. Kennedy MJ, Hughes RM, Peteya LA, Schwartz JW, Ehlers MD, Tucker CL. Rapid blue-light-mediated induction of protein interactions in living cells. Nat Methods 2010; 7:973-5; PMID:21037589; http:// dx.doi.org/10.1038/nmeth.1524.

80. Sinha DK, Neveu P, Gagey N, Aujard I, Le Saux T, Rampon $\mathrm{C}$, et al. Photoactivation of the CreER T2 recombinase for conditional site-specific recombination with high spatiotemporal resolution. Zebrafish 2010; 7:199-204; PMID:20441524; http://dx.doi. org/10.1089/zeb.2009.0632. 